Global Nest: the Int. J. Vol 1, No 2, pp 121-130, 1999 Copyright@ 1998 GLOBAL NEST Printed in Greece. All rights reserved

\title{
PROMOTION BY SODIUM IN EMISSION CONTROL CATALYSIS: The difference between alkanes and alkenes in the Pd-catalysed reduction of NO by hydrocarbons
}

\section{I.V. YENTEKAKIS ${ }^{*}$ \\ M. KONSOLAKIS1 \\ V. KIOUSIS1 \\ R.M. LAMBERT ${ }^{2}$ \\ M.S. TIKHOV2}

Received: $16 / 9 / 1998$

Accepted: 22/3/1999

\author{
1 ICE/HT-FORTH and Dept of Chemical Engineering, \\ University of Patras, 26500-Patras, GR \\ 2 Department of Chemistry, University of Cambridge, \\ Cambridge CB2 1EW, UK
}

* to whom all correspondence should be addressed, Fax: +(3061) 993255 e-mail:yyentek@iceht.forth.gr

\section{ABSTRACT}

The activity and selectivity of Pd catalysts supported on YSZ and dosed with different amounts of Na promoter has been investigated for the reduction of $\mathrm{NO}$ by alkenes $\left(\mathrm{C}_{3} \mathrm{H}_{6}\right)$ or alkanes $\left(\mathrm{CH}_{4}\right)$. It is found that $\mathrm{Na}$ strongly promotes the reduction of $\mathrm{NO}$ by $\mathrm{C}_{3} \mathrm{H}_{6}$. Rate increases by an order of magnitude are achievable, while the $\mathrm{N}_{2}$-selectivity is improved from $\sim 75 \%$ over the unpromoted Pd catalyst to $>95 \%$ over the optimally Na-promoted catalyst. With $\mathrm{CH}_{4}$ as the reductant, a very different behaviour is observed: for all loadings, $\mathrm{Na}$ induces only poisoning. The experimental data indicate that $\mathrm{Na}$ increases the strength of $\mathrm{NO}$ chemisorption relative to the hydrocarbons. This is accompanied by weakening of the $\mathrm{N}-\mathrm{O}$ bond, thus facilitating NO dissociation, which is proposed as the critical reaction-initiating step. According to this model the promoting or poisoning effect of $\mathrm{Na}$ depends on the interaction strength of the catalyst surface with the hydrocarbon. The different behaviour of propene and methane reflects the weaker interaction of alkanes with metal surfaces compared to that of alkenes. XPS and Auger data demonstrate that Na coverage increases monotonically with promoter loading and that there is no significant tendency for the promoter to agglomerate with increasing promoter loading. However, a very small but constant tendency to accumulate subsurface or dissolved $\mathrm{Na}$ was observed as the promoter loading is increased.

KEYWORDS: Sodium, NO reduction, Methane, Propene, Palladium, Promotion

\section{INTRODUCTION}

Heterogeneous catalysis has and will continue to play a major role in atmospheric pollution control. The catalytic reduction of $\mathrm{NO}_{\mathrm{X}}$ emissions produced by both stationary and automotive com- bustion processes is of major environmental importance (Taylor, 1993). Automotive exhaust catalytic converters - the so-called three-way catalyst (TWC) - employ a well established technolo- 
gy in controlling $\mathrm{NO}_{\mathrm{X}}, \mathrm{CO}$ and hydrocarbon emissions. This uses formulations based variously on $\mathrm{Pt}, \mathrm{Rh}$ and $\mathrm{Pd}$. With regard to $\mathrm{NO}_{\mathrm{X}}$ reduction, $\mathrm{Rh}$ is highly effective for NO dissociative chemisorption and is therefore the key component responsible for $\mathrm{NO}_{\mathrm{X}}$ reduction in conventional TWCs. On $\mathrm{Pd}$ this process exhibits strong structure sensitivity (Davies and Lambert, 1981), while Pt is relatively ineffective for the dissociative chemisorption of NO (Masel, 1995).

Considerable effort has been expended on finding materials for replacing or reducing the use of $\mathrm{Rh}$ in TWCs because of its scarcity and higher cost in comparison with $\mathrm{Pt}$ and $\mathrm{Pd}$. For the reasons given above, Pd is particularly promising in this regard; it is also relatively inexpensive. It is therefore of interest to discover means of enhancing the catalytic performance of $\mathrm{Pd}$ for the reduction of $\mathrm{NO}$, given that this metal is a notably effective catalyst for hydrocarbon oxidation. Efforts thus far have been focused on improving the catalytic properties of Pd by doping the support material with additives or by using supports other than $\mathrm{Al}_{2} \mathrm{O}_{3}$ (e.g. yttria-stabilised zirconia or YSZ) (Yentekakis et al., 1995; Pliangos et al., 1997). These strategies have indeed improved significantly the activity and selectivity of Pd for NO reduction to $\mathrm{N}_{2}$. Recently, Burch and Watling (1997) investigated the effects of a wide range of

\section{Table $1^{a}$. Properties of the $0.5 \mathrm{wt} \% \mathrm{Pd} / \mathrm{YSZ}$ cata- lysts \\ a. All the above surface characterisation measurements refer to used catalysts. \\ b. Based on the assumption that all $\mathrm{Na}$ is present at the surface and distributed uni- formly over the entire available area $(\mathrm{Pd}+\mathrm{YSZ})$, without any incorporation into the bulk. \\ c. Calculations based on a Pd surface atom density of $1.27 \times 10^{19}$ atoms $/ \mathrm{m}^{2}$}

promoters, including $\mathrm{Cs}$ and $\mathrm{K}$, on the Pt-catalysed reduction of NO by propene under lean burn conditions (i.e., in the presence of $5 \% \mathrm{O}_{2}$ ). They found no particular benefit with these two alkalis, and concluded that the manner in which the various promoters affect reactivity is unclear. More recently, Alexandrou et al. (1997) demonstrated significantly increased conversion in the $\mathrm{CO}+\mathrm{NO}$ reaction over $\mathrm{Na}$ promoted $\mathrm{Pd}$ and $\mathrm{Pt}$ supported catalysts.

Here we report Na-induced increases in reaction rate by up to an order of magnitude, as well as a significant enhancement in $\mathrm{N}_{2}$ selectivity, in the catalytic reduction of $\mathrm{NO}$ by propene over supported Pd catalysts. In contrast with this when an alkane $\left(\mathrm{CH}_{4}\right)$ was used as the reductant, we find that for all loadings $\mathrm{Na}$ induces only poisoning.

Previously, we used electrochemical promotion (EP) (Vayenas et al., 1992; Vayenas and Yentekakis, 1997) to investigate the efficacy of $\mathrm{Na}$ as a promoter for the Pt-catalysed NO reduction by CO (Palermo et al., 1996). Most recently (Yentekakis et al., 1997), the same technique was employed for $\mathrm{Na}$ promotion of $\mathrm{Pt}$ in the reduction of $\mathrm{NO}$ by $\mathrm{C}_{3} \mathrm{H}_{6}$. It was shown that $\mathrm{Na}$ supplied electrochemically from a $\beta^{\prime \prime}$-alumina solid electrolyte (a $\mathrm{Na}^{+}$ion conductor), strongly promoted both reactions: in effect Pt could be induced to behave like Rh. Activity enhancement of an order of magnitude and large increases in $\mathrm{N}_{2}$ selectivity were achieved.

Guided by these EP studies on Pt, there being no similar studies on Pd, we have chosen to investigate Na promotion of $\mathrm{NO}$ reduction by hydrocarbons $\left(\mathrm{C}_{3} \mathrm{H}_{6}\right.$ and $\left.\mathrm{CH}_{4}\right)$ over conventional dispersed $\mathrm{Pd}$ catalysts. (Propene is the industry standard for catalytic hydrocarbon oxidation studies and methane is relevant in the context of natural gas fuelled vehicles). Due to the very different interaction of alkanes and alkenes with metal surfaces, markedly different behaviour towards NO reduc-

\begin{tabular}{|c|c|c|c|c|c|}
\hline $\begin{array}{c}\text { Catalyst } \\
\text { code }\end{array}$ & $\begin{array}{c}\text { Na-loading } \\
(\mathrm{wt} \%)\end{array}$ & $\begin{array}{c}\text { Nominal Na } \\
\text { coverage }^{\mathrm{b}}(\%)\end{array}$ & $\begin{array}{c}\mathrm{H}_{2} \text { uptake } \\
\left(\mathrm{cm}^{3} \mathrm{STP} / \mathrm{g}\right)\end{array}$ & $\begin{array}{c}\text { Dispersion } \\
(\%)\end{array}$ & $\begin{array}{c}\text { Active surface area } \\
\left(\mathrm{m}^{2} / \mathrm{g}\right)\end{array}$ \\
\hline $\mathrm{C} 1$ & 0 & 0 & 0.106 & 20 & 0.45 \\
\hline $\mathrm{C} 2$ & 0.017 & 5 & 0.105 & 20 & 0.44 \\
\hline $\mathrm{C} 3$ & 0.034 & 10 & 0.131 & 25 & 0.55 \\
\hline $\mathrm{C} 4$ & 0.068 & 20 & 0.123 & 23 & 0.52 \\
\hline $\mathrm{C} 5$ & 0.102 & 30 & 0.127 & 24 & 0.54 \\
\hline
\end{tabular}


tion is expected. Thus we hope to uncover important aspects of NO/hydrocarbon catalytic chemistry. In addition, we seek to understand the mode of action of the Na promoter. The choice of support was dictated by recent studies, which show that YSZ maximizes the turnover activity of Pd for reactions of relevance to TWC chemistry (Yentekakis et al., 1995; Pliangos et al., 1997).

\section{MATERIALS AND METHODS}

Supported Pd catalysts used in this study were prepared by incipient wetness impregnation of the 8 mole\% yttria stabilised zirconia (YSZ) support (Zirconia Sales) using a $\mathrm{pH}=3$ solution of $\mathrm{PdCl}_{2}$ (Alfa Products). The solution was of appropriate strength so as to yield $0.5 \mathrm{wt} \%$ metal loading. Sodium was added to the catalysts by subsequent impregnation with $\mathrm{NaNO}_{3}$ solutions of suitable concentration. The suspensions were dried in a rotating flask by evaporation at $353 \mathrm{~K}$ and then overnight at $383 \mathrm{~K}$. These catalyst precursors were heated in flowing $\mathrm{He}\left(1 \mathrm{~h} / 673 \mathrm{~K} / 100 \mathrm{~cm}^{3} \mathrm{~min}^{-1}\right)$, followed by $\mathrm{H}_{2}$ reduction $\left(1 \mathrm{~h} / 673 \mathrm{~K} / 100 \mathrm{~cm}^{3} \mathrm{~min}^{-1}\right)$. Five samples with different $\mathrm{Na}$ loadings were produced (coded as C1-C5 in Table 1).

The metal dispersion was measured via $\mathrm{H}_{2}$ chemisorption at $333 \mathrm{~K}$ after reduction in $\mathrm{H}_{2}$ at 573 $\mathrm{K}$ for $30 \mathrm{~min}$ and degassing at $673 \mathrm{~K}$ for $30 \mathrm{~min}$. The hydrogen to metal ratio (H/M) was calculated by assuming a 1:1 hydrogen:metal stoichiometry. The $\mathrm{H}_{2}$ uptakes were determined by back-extrapolating the high pressure "plateau" part of the adsorption isotherm to zero. The BET surface area of the YSZ support was measured by $\mathrm{N}_{2}$ adsorption at 77 $\mathrm{K}$ and found to be $\sim 7 \mathrm{~m}^{2} \mathrm{~g}^{-1}$. The catalyst characterisation data are summarised in Table 1.

For purposes of convenient comparison, a nominal percentage surface coverage by $\mathrm{Na}$ has been calculated for each of the catalysts $\mathrm{C} 2-\mathrm{C} 5$ based on the assumption that all the promoter is present at the surface and distributed uniformly over the entire available area (Pd+YSZ), without any incorporation into the bulk.

Catalyst testing was performed in a flow apparatus, which consists of a feed unit, the reactor and an analysis unit utilizing on-line gas chromatography (Shimadzu-14B) and $\mathrm{CO}_{2}$-IR spectroscopy (Fisher-Rosemount, Binos 100 NDIR $\mathrm{CO}_{2}$ Analyser). The fixed-bed, single-pass, plug-flow reactor, consisting of a $0.4 \mathrm{~cm}$ ID quartz tube, was typically loaded with about $7.5 \mathrm{mg}$ of catalyst. The total gas-flow rate was high, typically $100-600 \mathrm{~cm}^{3} \mathrm{~min}^{-1}$, in order to minimize conversion of reactants and to eliminate mass- and heat-transfer effects during acquisition of the kinetic data. The absence of intraparticle and interparticle diffusional effects was experimentally confirmed by variation of catalyst particle size and gas flow rate. NO and hydrocarbon conversions were always bellow $25 \%$. Before measurements were taken, the catalysts were operated for 1 day in air and 5 days in a reactive gas mixture at $723 \mathrm{~K}$ to ensure stable operation. In addition, stability tests of Na-promoted catalysts at $723 \mathrm{~K}$ for up to 10 days showed no deterioration in both catalyst activity and selectivity.

XPS measurements were carried out in a VG ADES 400 UHV spectrometer system. The exreactor catalyst samples were pressed between two discs of high-purity aluminium; separating the discs then gave two specimens from each sample consisting of compacted powder adhering to the aluminum support. XP spectra were acquired with $\mathrm{MgK} \alpha$ radiation with the $\mathrm{Al}$ specimen support at ground potential; quoted binding energies are referred to the $\mathrm{Zr} 3 \mathrm{~d}_{5 / 2}$ emission from $\mathrm{YSZ}$ at $182.4 \mathrm{eV}$ BE. Typically, spectra were acquired by signal averaging over 10 scans.

\section{RESULTS \\ XPS and Auger data}

The XP spectra obtained from samples of the five ex-reactor catalysts provide useful information. Inserts (a) and (b) of Figure 1 show Na KLL Auger and $\mathrm{Na} 1 \mathrm{~s}$ photoelectron spectra, respectively, for each of the five catalysts and for the YSZ support alone. Although we cannot discriminate between $\mathrm{Na}$ on the metal and on the support, a notoriously difficult problem in catalyst characterisation, it is clear from both the Auger and photoelectron data that there is a monotonic increase in $\mathrm{Na}$ emission with increased $\mathrm{Na}$ loading. Additionally, this behaviour of the spectral intensities shows that there is no significant tendency for the promoter phase to agglomerate with increasing promoter loading. Background subtraction followed by quantification of these spectra shows that the ratios of the integrated Na KLL Auger and Na XP 1s intensities are as follows: $\mathrm{C} 2$ 


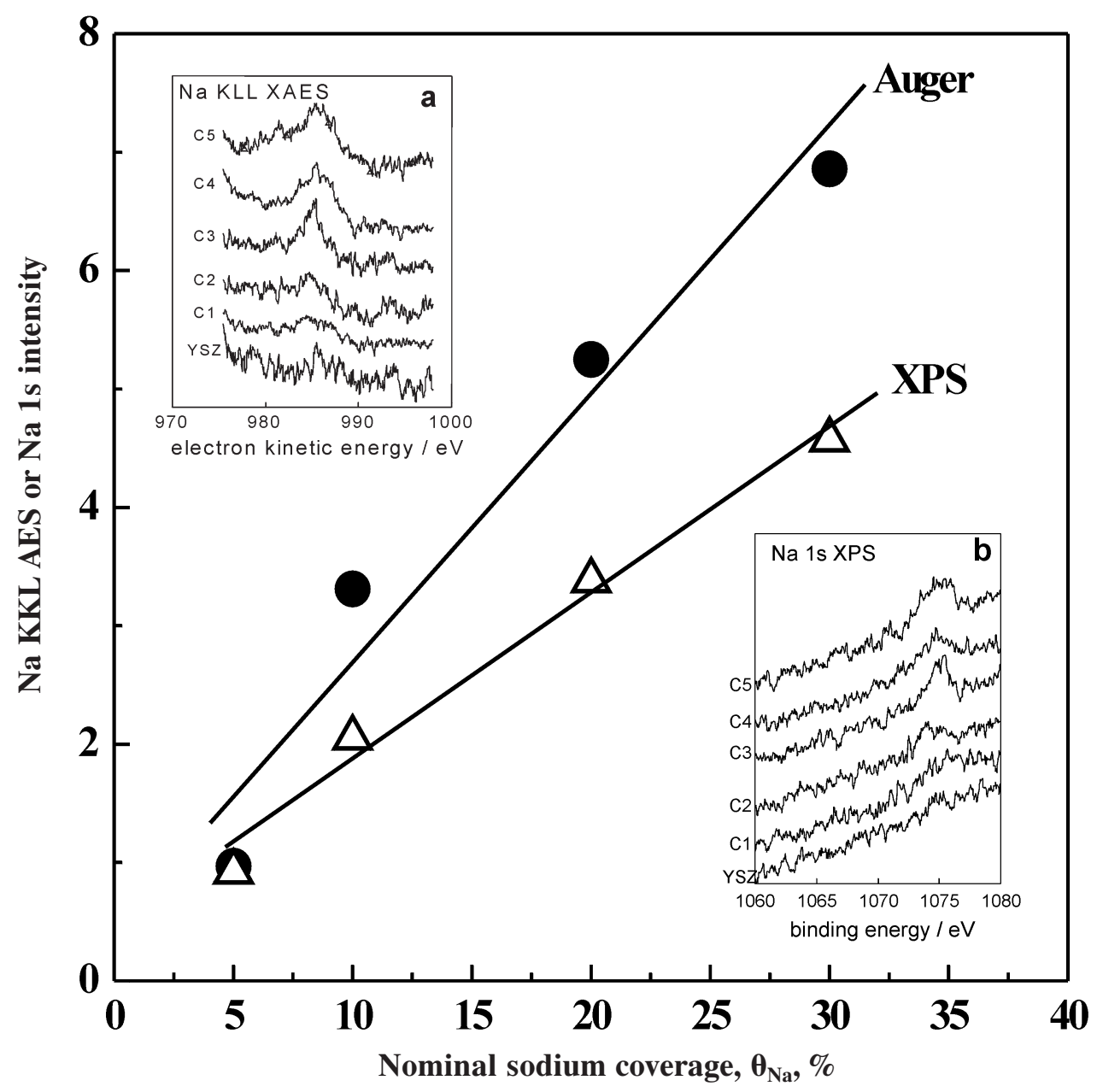

Figure 1. Dependence of integrated Na Auger and XP intensities on calculated nominal Na coverage. Insert (a): Na KLL X-ray excited Auger spectra of catalysts C1-C5 and of the YSZ support. Insert (b): Na 1s XP spectra of catalysts C1-C5 and of the YSZ support

$=1.1 \pm 0.3 ; \mathrm{C} 3-\mathrm{C} 5=1.5 \pm 0.3$ (Figure 1 ). The very different electron kinetic energies imply different sampling depths for the Auger and XP spectra: $\sim 10 \AA$ and $\sim 3 \AA$, respectively. One may therefore conclude that for the higher Na loadings (C3-C5) there is some tendency to accumulate subsurface $\mathrm{Na}$ relative to the lowest $\mathrm{Na}$ loading $(\mathrm{C} 2)$ and that the proportion of surface to subsurface $\mathrm{Na}$ is the same for C3 - C5.

\section{Effect of $\mathbf{N O}$ partial pressure $\left(\mathbf{P}_{\mathrm{NO}}\right)$}

$\mathrm{NO}+\mathrm{C}_{3} \mathrm{H}_{6}$ reaction: Figures 2a,b,c (A) show the effect of $\mathrm{P}_{\mathrm{NO}}$ on the $\mathrm{CO}_{2}, \mathrm{~N}_{2}$ and $\mathrm{N}_{2} \mathrm{O}$ turnover frequencies (TOF: molecules of product per surface Pd atom per second), respectively, for the five catalysts promoted by different amounts of $\mathrm{Na}$.
Figure 2d(A) illustrates the corresponding behaviour of the selectivity towards $\mathrm{N}_{2}$. The results very clearly show a pronounced promotion by sodium of both activity and selectivity, the extent of which is strongly dependent on the Na loading. Under our conditions, optimum performance is achieved at $0.068 \mathrm{wt} \% \mathrm{Na}$ (catalyst $\mathrm{C} 4,20 \%$ nominal $\mathrm{Na}$ coverage, Table 1), which causes up to ten-fold enhancement in the turnover rate of $\mathrm{CO}_{2}$ (Fig. $2 \mathrm{a}(\mathrm{A})$ ) and of $\mathrm{N}_{2}$ (Fig. 2b(A)), with respect of the unpromoted (Na-free) catalyst $\mathrm{C} 1$.

Although the magnitude of this effect depends on $\mathrm{P}_{\mathrm{NO}}$, decreasing with $\mathrm{P}_{\mathrm{NO}}$ beyond the optimal value, strong enhancement is present over a wide range of $\mathrm{P}_{\mathrm{C}_{3} \mathrm{H}_{6}}$ (see below, Fig. 3). At the same time, the rate of $\mathrm{N}_{2} \mathrm{O}$ formation remains practical- 

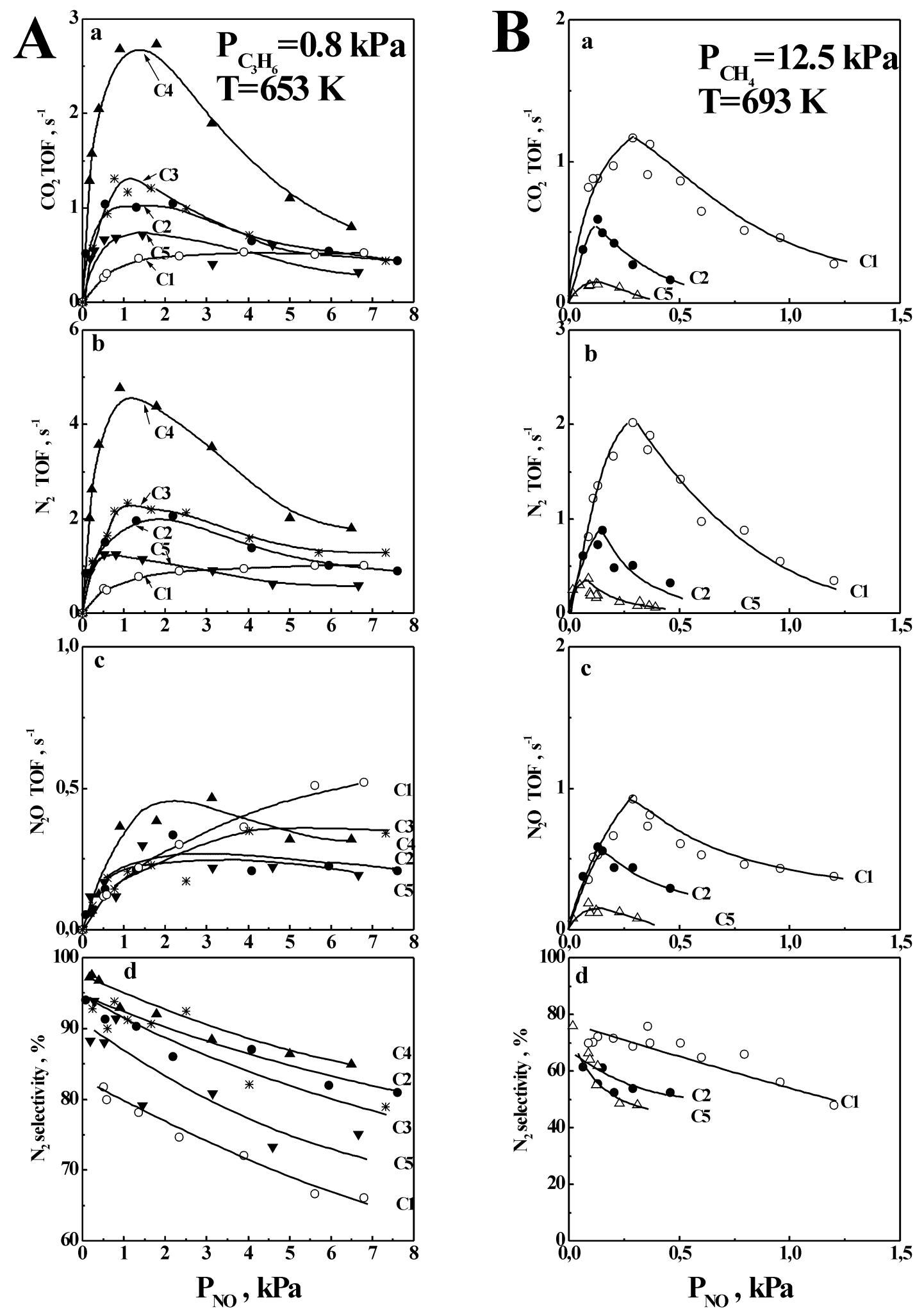

Figure 2. The effect of $\mathrm{P}_{\mathrm{NO}}$ on $\mathrm{CO}_{2}(\mathrm{a}), \mathrm{N}_{2}$ (b), $\mathrm{N}_{2} \mathrm{O}$ (c) TOFs and $\mathrm{N}_{2}$ selectivity (d), for catalysts C1-C5 during the Pd-catalysed reduction of $\mathrm{NO}$ by $\mathrm{C}_{3} \mathrm{H}_{6}$ (A) and by $\mathrm{CH}_{4}$ (B) 
ly unaffected (Fig. 2c(A)). This results in a significant increase in $\mathrm{N}_{2}$ selectivity (Fig. 2d(A)) defined as

$$
\mathrm{S}_{\mathrm{N}_{2}}=\mathrm{r}_{\mathrm{N}_{2}} /\left(\mathrm{r}_{\mathrm{N}_{2}}+\mathrm{r}_{\mathrm{N}_{2} \mathrm{O}}\right)
$$

where $\mathrm{r}_{\mathrm{N}_{2}}$ and $\mathrm{r}_{\mathrm{N}_{2} \mathrm{O}}$ are the production rates of $\mathrm{N}_{2}$ and $\mathrm{N}_{2} \mathrm{O}$, respectively.

It is apparent that $\mathrm{Na}$ promotion results in $\mathrm{S}_{\mathrm{N}_{2}}$ values in excess of $95 \%$ (at $0.068 \mathrm{wt} \% \mathrm{Na}$; catalyst $\mathrm{C} 4$ ) compared with $\sim 75 \%$ for the unpromoted catalyst $\mathrm{C} 1$. Note that in Figures $2 \mathrm{a}, \mathrm{b}(\mathrm{A})$, within the experimental scatter, it is clear that the Na-containing catalysts exhibit rate maxima within the $\mathrm{P}_{\mathrm{NO}}$ range studied, whereas the Na-free catalyst does not. Note also that promotion is maximized for a sodium content of $0.068 \mathrm{wt} \%$ (Catalyst C4, $20 \%$ nominal Na coverage); further increase in the sodium loading leads to poisoning of the system.

$\mathrm{NO}+\mathrm{CH}_{4}$ reaction: Figure 2(B) shows the kinetics of the $\mathrm{NO}+\mathrm{CH}_{4}$ reaction upon varying $\mathrm{P}_{\mathrm{NO}}$. The results for the $\mathrm{NO}+\mathrm{C}_{3} \mathrm{H}_{6}$ reaction are also shown (Fig. 2(A)) for comparison purposes. In contrast with the $\mathrm{C}_{3} \mathrm{H}_{6}$ case, it is clear that $\mathrm{Na}$ induces poisoning of $\mathrm{Pd}$ for $\mathrm{NO}$ reduction when using $\mathrm{CH}_{4}$ as the reductant. This rate inhibition is accompanied by a monotonic shift of the value of the NO partial pressure corresponding to the rate maximum. This reflects a strengthening of the NO chemisorption bond as a result of $\mathrm{Na}$ loading of the catalyst. In a similar way, the $\mathrm{N}_{2} / \mathrm{N}_{2} \mathrm{O}$ selectivity of the Na-containing catalysts (Fig. 2d(B)) is always less than that of the Na-free catalyst $\mathrm{C}$. The characteristic rate maxima are an indication of competitive adsorption of both $\mathrm{NO}$ and $\mathrm{CH}_{4}$ on the Pd surface. A comparison of the trends shown in Figures 2(B) and 3(B) indicates that under these conditions the adsorption of $\mathrm{NO}$ on Pd is significantly stronger than that of $\mathrm{CH}_{4}$. In contrast with this, a similar comparison of the results in Figures 2(A) and 3(A), which depict the corresponding $\mathrm{NO}+\mathrm{C}_{3} \mathrm{H}_{6}$ data, confirms that the adsorption strengths of $\mathrm{NO}$ and $\mathrm{C}_{3} \mathrm{H}_{6}$ are similar.

\section{Effect of hydrocarbon partial pressure $\left(P_{H C}\right)$}

$\mathrm{NO}+\mathrm{C}_{3} \mathrm{H}_{6}$ reaction: Figures $3 \mathrm{a}, \mathrm{b}, \mathrm{c}$ (A) show the $\mathrm{CO}_{2}, \mathrm{~N}_{2}$ and $\mathrm{N}_{2} \mathrm{O}$ rates respectively, for the same five catalysts (Table 1) as a function of $\mathrm{P}_{\mathrm{C}_{3} \mathrm{H}_{6}}$, for a fixed $\mathrm{P}_{\mathrm{NO}}=1.0 \mathrm{kPa}$. Again, a systematic enhancement of turnover rate as a function of added $\mathrm{Na}$ is apparent, with the Na-promoted catalyst $\mathrm{C} 4$ exhibiting the highest $\mathrm{CO}_{2}$ and $\mathrm{N}_{2}$ rate enhancement $(\sim 10$ times the rate shown by the unpromoted catalyst over almost the entire range of $\mathrm{P}_{\mathrm{C}_{3} \mathrm{H}_{6}}$ ). The corresponding $\mathrm{N}_{2} \mathrm{O}$ formation rate is rather insensitive to $\mathrm{Na}$ loading (Fig. 3c(A)), resulting in the $\mathrm{N}_{2}$ selectivity behaviour shown in Fig. $3 \mathrm{~d}(\mathrm{~A})$ : catalyst $\mathrm{C} 4$ delivers up to $\sim 95 \% \mathrm{~N}_{2}$ selectivity compared with $\sim 80 \%$ for the unpromoted catalyst.

$\mathrm{NO}+\mathrm{CH}_{4}$ reaction: The kinetics of the $\mathrm{NO}+\mathrm{CH}_{4}$ reaction upon varying $\mathrm{P}_{\mathrm{CH}_{4}}$ at constant $\mathrm{P}_{\mathrm{NO}}=0.3 \mathrm{kPa}$ are also shown in Fig. 3(B). A linear rate dependence on $\mathrm{P}_{\mathrm{CH}_{4}}$ is clear. Comparison with the $\mathrm{P}_{\mathrm{NO}}$ dependence (Fig. 2(B)), which exhibits well-defined rate maxima (appearing at very low ratios of $\mathrm{P}_{\mathrm{NO}} / \mathrm{P}_{\mathrm{CH}_{4}}<0.03$ ) strongly supports the conclusion of weak methane adsorption on the metal surface, relative to NO. Na addition causes a monotonic decrease in the rates: sodium always poisons the reduction of NO by methane. This is strikingly different from the response of the $\mathrm{NO}+\mathrm{C}_{3} \mathrm{H}_{6}$ reaction, where strong initial promotion by sodium is observed for low to intermediate loadings (Fig. 3(A)).

A very interesting feature of Fig. 3(B) is the threshold partial pressure of methane $\left(\mathrm{P}_{\mathrm{CH}_{4}}{ }^{*}\right)$, below which the activity for $\mathrm{NO}$ reduction vanishes. It can be seen that $\mathrm{Na}$ exerts a pronounced effect on the value of $\mathrm{P}_{\mathrm{CH}_{4}}{ }^{*}$. This is thought to be the partial pressure of methane, which is required to overcome O-poisoning of the surface, thus allowing in initiation of the surface reaction $[\mathrm{NO}(\mathrm{a}) \rightarrow \mathrm{N}(\mathrm{a})+\mathrm{O}(\mathrm{a})]$. The weak interaction of $\mathrm{CH}_{4}$ with the surface, as well as the shift of the $\mathrm{P}_{\mathrm{CH}_{4}}$ * to larger values upon increasing the $\mathrm{Na}$ loading, are in accord with this explanation.

Although the selectivity of the Na-containing catalysts (C2-C5, Fig. 3d(B)) is always below that of the Na-free catalyst $(\mathrm{C} 1)$, the scatter in the data precludes conclusions to be drawn about the dependence of this effect on $\mathrm{Na}$ content.

\section{DISCUSSION}

The present results show that the Pd-catalysed reduction of NO by hydrocarbons can be markedly affected by sodium addition to the catalyst. In the 

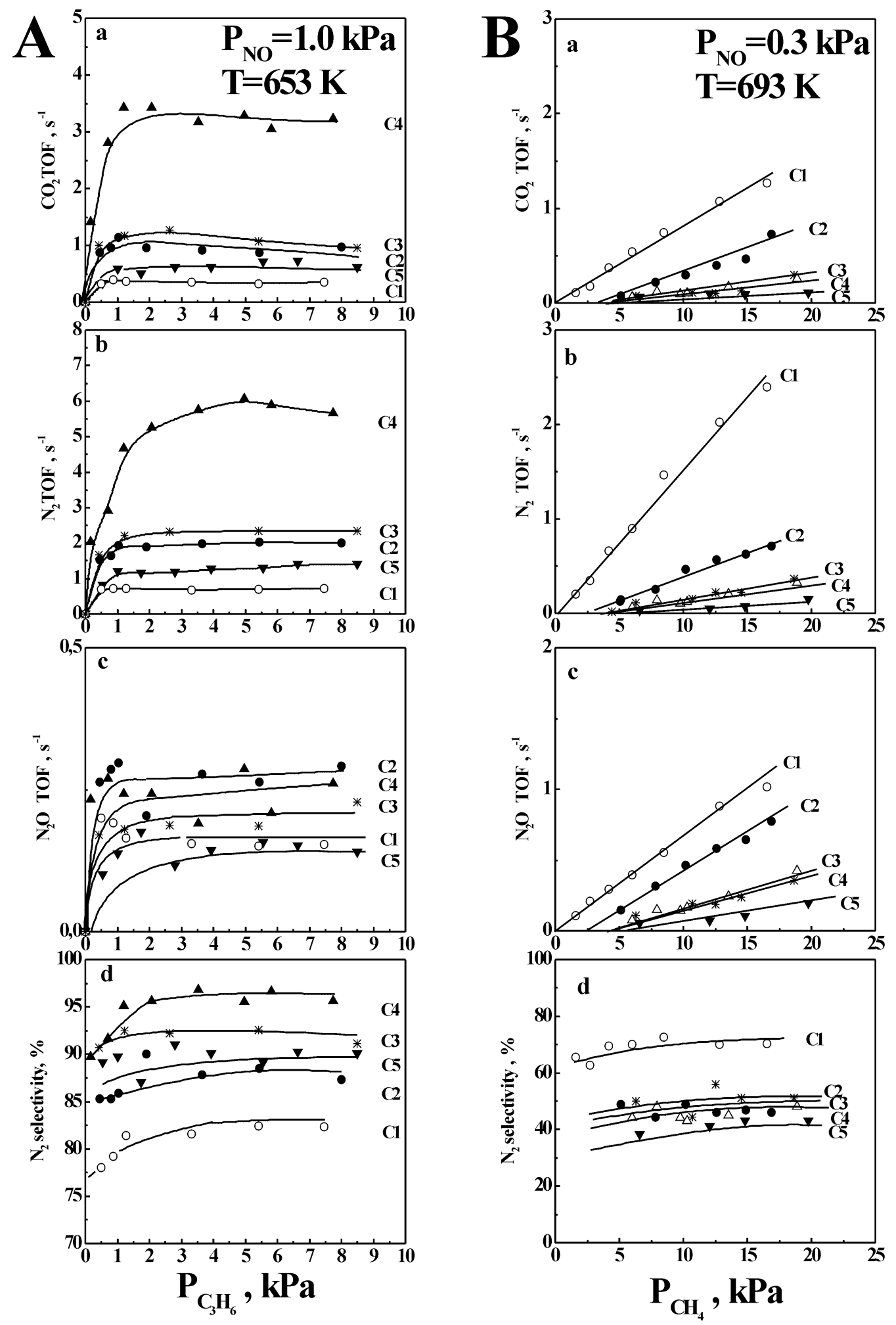

Figure 3. The effect of $\mathrm{P}_{\mathrm{HC}}$ on $\mathrm{CO}_{2}$ (a), $\mathrm{N}_{2}$ (b), $\mathrm{N}_{2} \mathrm{O}$ (c) TOFs and $\mathrm{N}_{2}$ selectivity (d), for catalysts C1-C5, during the Pd-catalysed reduction of $\mathrm{NO}$ by $\mathrm{C}_{3} \mathrm{H}_{6}$ (A) and by $\mathrm{CH}_{4}$ (B) 
case of using $\mathrm{CH}_{4}$ as the reductant, sodium behaves as a strong poison at all $\mathrm{Na}$ loadings. In marked contrast, very pronounced promotional effects of Na were observed when an alkene $\left(\mathrm{C}_{3} \mathrm{H}_{6}\right)$ was used as the reductant. In this case the $\mathrm{Na}$-induced rate enhancements were very large. Thus, with propene the maximum observed catalytic rate enhancement $\varrho$, defined as the ratio between the promoted $r$ and the un-promoted $r_{0}$ catalytic rate,

$$
\varrho=r / r_{o}
$$

is of the order of 10 for both $\mathrm{N}_{2}$ and $\mathrm{CO}_{2}$ formation rates (Figs. 2 and 3). The corresponding effect of $\mathrm{Na}$ addition on the rate of $\mathrm{N}_{2} \mathrm{O}$ formation is much lower ( $\mathrm{2} 2)$. This results in a significant increase in $\mathrm{S}_{\mathrm{N}_{2}}$ of the system, which increases from $\sim 75 \%$ over the unpromoted (Na-free) catalyst $\mathrm{C} 1$ to $>95 \%$ for catalyst C4 (Figs. 2d and 3d).

These data bear a close and very interesting resemblance to those obtained by electrochemical promotion (EP) of a Pt catalyst film supplied with $\mathrm{Na}$ from a solid electrolyte. Indeed, it was this EP work which prompted the present investigation. Thus, we have shown that the reduction of NO by propene (Yentekakis et al., 1997) as well as by CO (Palermo et al., 1996) over a Pt catalyst film in contact with $\beta^{\prime \prime}$-alumina (a $\mathrm{Na}^{+}$ion conductor) exhibits large increases in rate and selectivity when $\mathrm{Na}$ is supplied to the metal surface. Our EP findings led us to conclude that Na promotion is due to enhanced metal-NO interaction mediated by the sodium, as verified by experiments on $\operatorname{Pt}\{111\} /$ $\mathrm{Na}+\mathrm{NO}$ (Harkness and Lambert, 1997) and supported by theory (Lang et al., 1985). We argued that $\mathrm{Na}$ increases the strength of $\mathrm{NO}$ chemisorption relative to propene (or $\mathrm{CO}$ ), an effect which is accompanied by weakening of the N-O bond, thus facilitating NO dissociation on the metal surface. Given that the polycrystalline Pt film consisted mainly of large crystallites $(\sim 1 \mu \mathrm{m})$ whose external surfaces are dominated by low index planes known to be relatively ineffective for NO dissociation, the effect of $\mathrm{Na}$ is to activate previously inactive crystal planes. Thus $\mathrm{Na}$ promotion is due to (i) increased coverage of $\mathrm{NO}$ in the presence of strongly adsorbing propene (or $\mathrm{CO}$ ), (ii) triggering of NO dissociation, which is the key reaction-initiating step. Once $\mathrm{O}(\mathrm{a})$ is produced it is consumed by adsorbed propene (or $\mathrm{CO}$ ) accompanied by $\mathrm{N}(\mathrm{a})$ recombination or reaction with $\mathrm{NO}$ (a) to yield $\mathrm{N}_{2}$ and $\mathrm{N}_{2} \mathrm{O}$, respectively.

In the present case the promotional effect of $\mathrm{Na}$ exhibits a maximum as a function of $\mathrm{Na}$ content at a sodium loading of $0.068 \mathrm{wt} \%(20 \%$ nominal $\mathrm{Na}$ coverage). Increasing the $\mathrm{Na}$ content beyond this level leads to poisoning (Figs. 2 and 3). This is entirely analogous to the corresponding EP data for NO + propene (Yentekakis et al., 1997) and reflects two opposing effects, namely (i) the Na-induced activation of previously inactive metal sites as described above, and (ii) the accumulation of $\mathrm{Na}$ surface compounds, which progressively block the surface to adsorption of the reactants. XPS studies involving in situ transfer of promoted and poisoned ex-reactor EP catalysts to the spectrometer analysis chamber show (Yentekakis et al., 1997) that in the case of $\mathrm{NO}+$ propene the $\mathrm{Na}$-containing promoting (or poisoning) phase consists principally of a mixture of $\mathrm{NaNO}_{2}$ and $\mathrm{NaNO}_{3}$, along with some $\mathrm{Na}_{2} \mathrm{CO}_{3}$. It therefore seems reasonable to propose that similar phenomena occur at the surface of our Na-promoted Pd catalysts. In other words, there is a promotion by low to moderate amounts of $\mathrm{Na}$ nitroxy compounds and a poisoning due to site blocking by these same compounds above some optimum alkali loading. Our XPS data are entirely consistent with this interpretation. They demonstrate that there is no tendency to accumulate dissolved or subsurface $\mathrm{Na}$ as the promoter loading is varied. The surface coverage by $\mathrm{Na}$ does indeed increase with promoter loading, and the catalytic activity and selectivity pass through a maximum.

Two observations confirm the proposed model for Na promotion:

(i) Under reaction conditions there is clear evidence for competitive adsorption of the $\mathrm{NO}$ and hydrocarbon $\left(\mathrm{C}_{3} \mathrm{H}_{6}\right.$ or $\left.\mathrm{CH}_{4}\right)$ on the $\mathrm{Pd}$ surface. This is manifested by the Langmuir-Hinshelwood kinetic behaviour (Fig. 2), whereby the reaction rates exhibit maxima as a function of $\mathrm{P}_{\mathrm{NO}}$. Interestingly, in both cases these rate maxima shift to lower NO partial pressures as the sodium content of the catalyst is increased, reflecting an increase in the binding of $\mathrm{NO}$ relative to $\mathrm{C}_{3} \mathrm{H}_{6}$ or $\mathrm{CH}_{4}$ with increasing $\mathrm{Na} / \mathrm{Pd}$ ratio, i.e., $\mathrm{Na}$ enhances $\mathrm{NO}$ chemisorption versus hydrocarbon chemisorption on Pd. This is exactly the kind of behaviour one would expect in 
the case of an electropositive promoter, i.e., the chemisorption strength of electron donors (hydrocarbon in the present case) should be decreased whereas the chemisorption of electron acceptors (NO and its dissociation products) should be enhanced.

(ii) The model is also strongly supported by the behaviour observed in the catalytic reduction of $\mathrm{NO}$ by $\mathrm{CH}_{4}$. As is clear from Figs. 2 and 3, sodium induces only poisoning at all $\mathrm{Na}$ loadings. This reflects the weak interaction of $\mathrm{CH}_{4}$ with the metal surface, relative to NO. Thus even at low $\mathrm{P}_{\mathrm{NO}}$, the catalyst is predominantly covered by NO. As a result, any further enhancement of the Pd-NO bond strength induced by sodium addition results in poisoning. With alkenes, however, due to their much stronger interaction with the metal surface, a wide range of conditions exist for which the surface is predominantly covered by hydrocarbon. Na addition then results in promotion as discussed above.

It is remarkable that such close similarities exist between the behaviour of Pt electrochemically promoted with Na (Yentekakis et al., 1997) and the conventional highly dispersed catalysts investigated in the present study. These similarities include the overall kinetic behaviour and the dependence of activity and selectivity on Na loading. Recall that EP is applied to thin continuous films of the catalytic metal to which the promoting species (in this case $\mathrm{Na}$ ) is supplied by spillover from a suitable solid electrolyte. Among other things, our results serve to validate further the interpretation offered for the EP phenomenon (Vayenas et al., 1992; Vayenas and Yentekakis, 1997). More importantly, they demonstrate that the insight obtained from EP studies can be used to design successfully effective catalyst formulations, which were previously untried, thus opening up new areas for investigation (Yentekakis et al., 1998; Konsolakis et al., 1998).

A comment concerning the effect of temperature is in order. One might expect a degree of temperature dependence of the promotion effect. This could be due to (a) possible redistribution of the $\mathrm{Na}$ surface compounds, (b) in the propene/NO case one might predict that higher temperatures should tend to reduce the strength of the promotion effect, since NO dissociation on unpromoted sites should also become significant. However, it is likely that other temperature-dependent effects would also contribute to the overall behaviour so that predictions cannot be made with certainty. Equally, a detailed study of the high-temperature stability of these catalysts is called for in order to evaluate their potential practical utility. This is being addressed by current work in our laboratory.

\section{CONCLUSIONS}

For highly dispersed Pd catalysts supported on YSZ, addition of Na strongly promotes both activity and $\mathrm{N}_{2}$ selectivity in the reduction of $\mathrm{NO}$ by propene. Catalyst performance becomes optimal at a sodium loading of $0.068 \mathrm{wt} \%, 20 \%$ nominal $\mathrm{Na}$ coverage. With $\mathrm{CH}_{4}$ as the reductant, all Na loadings induce only poisoning. In both cases the kinetic data are understandable in terms of Na-induced dissociation of $\mathrm{NO}$ as the reaction-initiating step.

Electron spectroscopic data show that coverage of the catalyst by $\mathrm{Na}$ increases monotonically with promoter loading, and that there is no tendency towards promoter agglomeration at the higher loadings. Additionally, they demonstrate a small but constant tendency to accumulate subsurface or dissolved $\mathrm{Na}$ as the promoter loading is increased above 5\% nominal Na coverage.

In all respects the behaviour closely resembles that observed for the $\mathrm{NO}+\mathrm{C}_{3} \mathrm{H}_{6}$ reaction under conditions of electrochemical promotion by $\mathrm{Na}$. The present results therefore validate the interpretation offered for the EP system. They also show how insight gained from the latter may guide the formulation of new types of conventional catalysts.

\section{ACKNOWLEDGMENTS}

IVY thanks the Department of Chemical Engineering, University of Patras and ICEHT/FORTH for financial support of this project. This work was also supported in part under grant number GR/K45562 awarded by UK EPSRC.

\section{REFERENCES}

Alexandrou, F.A., Papadakis, V.G., Verykios, X.E. and Vayenas, C.G. (1997). The promotional effect of Na for the $\mathrm{NO}$ reduction by $\mathrm{CO}$ on supported $\mathrm{Pt}, \mathrm{Pd}$ and $\mathrm{Rh}$ catalyst, Proc. 4th Int. Cong. on Catalysis \& Automotive Pollution Control (Eds., N. Kruse et al.), Brussels, Vol. 2, 7-12. 
Burch, R. and Watling, T.C. (1997). The effect of promoters on $\mathrm{Pt} / \mathrm{Al}_{2} \mathrm{O}_{3}$ catalysts for the reduction of $\mathrm{NO}_{\text {by }} \mathrm{C}_{3} \mathrm{H}_{6}$ under lean-burn conditions, Appl. Catal. B, 11, 207-216.

Davies, P.W. and Lambert, R.M. (1981). Structural stability and chemisorption properties of a stepped Pd surface: oxygen and NO on Pd(331), Surf. Sci., 110, 227-249.

Harkness, I.R. and Lambert, R.M. (1997). Chemisorption and reactivity of nitric oxide on Na-dosed Pt(111), J. Chem. Soc. Faraday Trans., 93, 1425-1429.

Konsolakis, M., Palermo, A., Tikhov, M., Lambert, R.M. and Yentekakis, I.V. (1998). Electrochemical vs conventional promotion: A new tool to design effective high dispersed conventional catalysts, Ionics, 4, 148156.

Lang, N.D., Holloway, S. and Norskov, J.K. (1985). Electrostatic adsorbate-adsorbate interactions: The poisoning and promotion of the molecular adsorption reaction, Surf. Sci., 150, 24-38.

Masel, R.I. (1986). An experimental test of various models of the active site for NO reduction on platinum, Catal. Rev.- Sci. Eng., 28, 335-369.

Palermo, A., Lambert, R.M., Harkness, I.R., Yentekakis, I.V., Marina, O. and Vayenas, C.G. (1996). Electrochemical promotion by $\mathrm{Na}$ of the Pt-catalysed reaction between $\mathrm{CO}$ and NO, J. Catal., 161, 471479.

Pliangos, C., Yentekakis, I.V., Papadakis, V.G., Vayenas, C.G. and Verykios, X.E. (1997). Support induced promotional effects on the activity of automotive exhaust catalysts: I. The case of oxidation of light hydrocarbons $\left(\mathrm{C}_{2} \mathrm{H}_{4}\right)$, Appl. Catal. B, 14, 161-173.

Taylor, K.C. (1993). Nitric oxide catalysis in automotive exhaust systems, Catal. Rev.-Sci. Eng., 35, 457-481.

Vayenas, C.G., Bebelis, S., Yentekakis, I.V. and Lintz, H.-G. (1992). Non-Faradaic electrochemical modification of catalytic activity, Catal. Today, 11, 303-445.

Vayenas, C.G. and Yentekakis, I.V. (1997). Handbook of Heterogeneous Catalysis (Eds., G. Ertl et al.), Wiley-VCH, Weinheim/New York, 3, 1310-1325.

Yentekakis, I.V., Pliangos, C.A., Papadakis, V.G., Verykios, X.E. and Vayenas, C.G. (1995). Support and NEMCA induced promotional effects on the activity of automobile exhaust catalysts, Stud. Surf. Sci. Catal., 96, 375-385.

Yentekakis, I.V., Palermo, A., Filkin, N.C., Tikhov, M.S. and Lambert, R.M. (1997). In situ electrochemical promotion by sodium of the Pt-catalysed reduction of NO by propene, J. Phys. Chem. B, 101, 3759-3768.

Yentekakis, I.V., Lambert, R.M., Tikhov, M., Konsolakis, M. and Kiousis, V. (1998). Promotion by Na in emission control catalysis, J. Catal., 176, 82-92. 